\title{
ANALISIS PERHITUNGAN HEATRATE PADA TURBIN UAP BERDASARKAN PERFORMANCE TEST UNIT 1 DI PT. INDONESIA POWER UBOH UJP BANTEN 3 LONTAR
}

\author{
JAMALUDIN \& REZA PANGESTU DH \\ Program Studi Teknik Mesin, Fakultas Teknik, Universitas Muhammadiyah Tangerang \\ Jl. Perintis Kemerdekaan I/33 Cikokol-Tangerang \\ Email: jamaludinpermana14@yahoo.com
}

\begin{abstract}
ABSTRAK
Heat rate mempunyai peranan yang sangat penting pada pembangkit listrik. Heatrate merupakan ukuran dari thermal sebagai jumlah dari energi bahan bakar yang dibutuhkan untuk menghasilkan sejumlah energi listrik.Satuan heatrate yaitu $\mathrm{kJ} / \mathrm{kWh}$. Penelitian ini bertujuan untuk mengetahui nilai turbineheatrate pada turbin uap berdasarkan performance test. Pengambilan data dilakukan dengan metode observasi di PT. INDONESIA POWER UJP BANTEN 3 LONTAR (PLTU) pada pembangkit unit 1. Untuk mengetahui nilai turbine heatrate pada turbin uap digunakan metode perhitungan berdasarkan massa uap "steam" dan energi dalam "entalphy" yang masuk dan keluar turbin dengan daya keluaran generator (output generator). Turbine heatrate berbanding terbalik dengan efisiensi, yang artinya semakin kecil nilai turbine heatrate maka semakin baik efisiensi pembangkit tersebut, sebaliknya semakin tinggi nilai turbine heatrate maka efisiensi pembangkit tersebut buruk. Hasil Analisa yang didapat pada turbine heatrate berdasarkan performance test unit 1dengan nilai terendah (terbaik) yaitu pada bulan Januari dengan nilai 8252.61 $\mathrm{kJ} / \mathrm{kWh}$, dan nilai tertinggi (terburuk) yaitu pada bulan Maret dengan nilai $8911.99 \mathrm{~kJ} / \mathrm{kWh}$. Kenaikan dan penurunan turbin heatrate tidak begitu signifikan.
\end{abstract}

Kata Kunci: Heatrate, Turbin Uap, Turbine, Heatrate, Performance Test.

\section{PENDAHULUAN}

Energi yang paling dibutuhkan manusia untuk menunjang kehidupan salah satunya adalah energi listrik.Manusia membutuhkan energi listrik untuk kepentingan rumah tangga, industri serta untuk menunjang sarana prasarana yang lainnya. Kebutuhan hidup manusia semakin meningkat, peningkatan kebutuhan manusia juga diikuti dengan kebutuhan energi yang juga semakin meningkat. Energi yang besar serta penggunaannya yang terus menerus tidak dapat tersedia secara alami. Oleh sebab itu dibutuhkan pembangkit listrik yang handal.

Turbin uap yang digunakan pada PLTU bekerja secara kontinyu untuk menghasilkan daya yang maksimal.Turbin uap merupakan salah satu mesin konversi energi karena dapat mengubah energi kalor menjadi energi mekanik dan selanjutnya energi mekanik diubah menjadi energi listrik pada generator.

Secara umum heatrate didefinisikan sebagai total panas input yang masuk ke dalam sebuah sistem dibagi dengan total daya yang dibangkitkan oleh sistem tersebut, dengan satuan Btu/kWh atau $\mathrm{kJ} / \mathrm{kWh}$ atau $\mathrm{kcal} / \mathrm{kWh}$ (satuan yang biasa dipakai oleh industri pembangkitan listrik di Indonesia). Walaupun definisi heatrate di atas terlihat sederhana, namun parameter-parameter yang digunakan untuk menghitung heatrate sangatlah banyak, sedangkan turbin heatrate didefinisikan sebagai jumlah kalor yang dibutuhkan untuk menghasilkan energi listrik sebesar $1 \mathrm{kWh}$.

Masing-masing unit PLTU BANTEN 3 
LONTAR melakukan performance test pada tiap-tiap unit turbin uap. Heatrate dapat dihitung dengan metode input-output, turbin heatrate, dan specific fuel consumption (SFC). Pengujian heatrate dilakukan untuk mengetahui berapa besar input energi panas dari bahan bakar yang dibutuhkan untuk menghasilkan listrik sebesar $1 \mathrm{kWh}$. Uji heatrate dilakukan pada kondisi yang spesifik, baik bahan bakar, lokasi pembangkit listrik, kapasitas pembangkit maupun variasi beban pembangkit.

Pembangkit Listrik Tenaga Uap (PLTU) Banten 3 Lontar Unit 1 merupakan pembangkit listrik dengan bahan bakar batubara yang memanfaatkan fluida kerja berupa uap (steam) untuk menggerakkan turbin yang bertindak sebagai penggerak mula yang kemudian turbin akan memutar rotor generator untuk menghasilkan listrik. Dalam proses produksi listrik, banyak terjadi proses konversi energi. Proses konversi energi sendiri merupakan proses perubahan energi berdasarkan perubahan bentuk dan sifatnya. Berawal dari energi kimia yang terkandung dalam batubara yang dikonversi menjadi energi kalor dalam proses pembakaran. Kemudian dikonversi lagi menjadi energi kinetik berupa aliran uap (steam), selanjutnya dikonversi menjadi energi mekanik melalui putaran turbin dan pada proses akhirnya energi mekanik tersebut dikonversikan menjadi energi listrik melalui generator. Pembangkit listrik tenaga uap termasuk dalam kategori "thermal plant", karena pembangkit listrik ini memanfaatkan panas hasil pembakaran bahan bakar batubara dan udara furnace (tungku pembakaran) yang kemudian digunakan untuk memanaskan pipa-pipa berisi air/uap di dalam boiler.

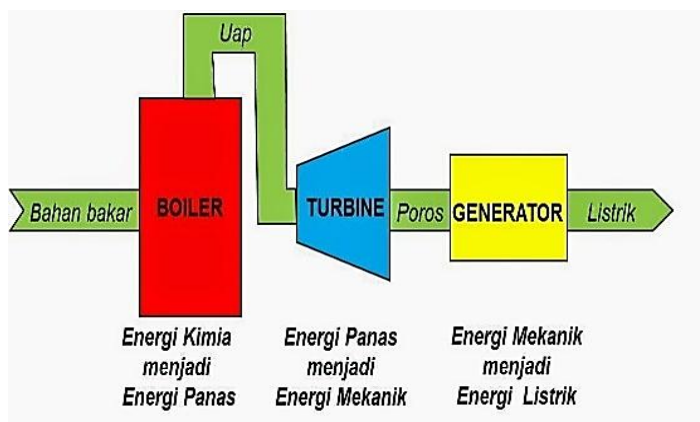

Gambar 2.1 Proses Konversi Energi PLTU

Proses konversi energi yang terjadi di dalam boiler, bahan bakar yang dimasukkan ke dalam boiler digunakan dalam proses pembakaran dan pemanasan air akan mengubah air umpan boiler menjadi uap atau steam. Uap tersebut masih dipanaskan lagi dan dinaikkan tekanannya dengan pemanasan lanjutan sehingga dihasilkan uap superheat atau uap kering sehingga uap tersebut memiliki energi yang cukup untuk memutar turbin. Uap yang keluar dari turbin kemudian masuk dalam kondensor untuk diubah fasanya menjadi air kembali.Setelah itu, air tersebut dipompa kembali ke boiler untuk dipanaskan dan diubah menjadi uap guna memutar turbin lagi.

Siklus Rankineuntuk pembangkit PLTU BANTEN 3 Lontar menggunakan kedua siklus diatas, dimana siklus rankinedengan pemanasan ulang terjadi di reheater boiler sedangkan siklus rankine dengan rankine regenerative terjadi di economizer. Diagram $\mathrm{T}-\mathrm{s}$ untuk pembangkit PLTU BANTEN 3, Lontar dapat digambarkan sebagai berikut:

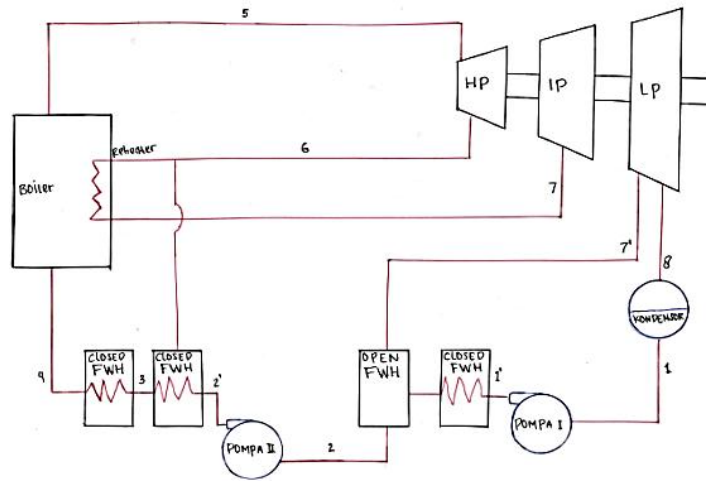

Gambar 2.2. Siklus Rankine Regenerative di PLTU Banten 3 Lontar.

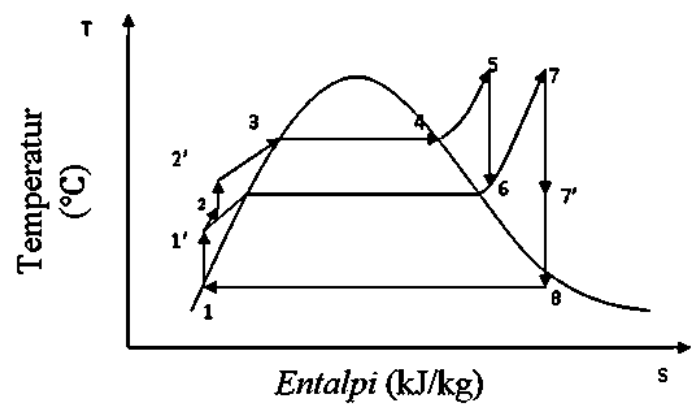

Gambar 2.3 T-S Siklus Rankine Regenerative Di PLTU BANTEN 3 LONTAR

Keterangan gambar:

1) Proses $1-1$ ' : Penaikan tekanan pada air menggunakan condensate extaction pump.

2) Proses 1'-2 : Pemanasan air low pressure heater. 
3) Proses 2-2' : Penaikan tekanan air menggunakan boiler feed pump.

4) Proses 2' - 3 : Pemanasan air pada high pressure heater dan padaeconomizer.

5) Proses 3-4 : Pemanasan air menjadi uap air pada wall tube dan downcomer didalam boiler.

6) Proses 4-5 : Pemanasan uap air menjadi uap panas lanjut (superheated steam)padasuperheater.

7) Proses 5-6 : Proses ekspansi di dalam high pressureturbine.

8) Proses 6-7 : Pemanasan kembali uap yang keluar dari high pressure turbine yang terjadi dalam reheater.

9) Proses 7-7' : Ekspansi uap yang keluar dari reheater di dalamintermediate pressure turbine.

10) Proses 7' -8 : Ekspansi uap di dalam low pressure turbine tanpa mengalami pemanasan ulang.

11) Proses 8-1 : Pendinginan uap menjadi air didalam condenser.

\section{Turbine Heatrate}

Turbine heatrate adalah jumlah kalor yang dibutuhkan untuk memproduksi listrik sebesar $1 \mathrm{kWh}$ dan dinyatakan dalam satuan $(\mathrm{kJ} / \mathrm{kWh})$. Turbine heatrate menunjukkan perbandingan dari energi total yang digunakan untuk memutar turbin, dengan energi listrik yang dihasilkan oleh generator dan dinyatakan dalam $\mathrm{kJ} / \mathrm{kWh}$.

Turbine heat rate dapat dikalkulasi dengan persamaan:

$$
\begin{gathered}
H R_{T}=\left(\dot{m}_{1} \times h_{1}+\dot{m}_{3} \times h_{3}\right)- \\
\left(\dot{m}_{f} \times h_{f}+\dot{m}_{2} \times h_{2}+\dot{m}_{i s} \times h_{s s)}\right.
\end{gathered}
$$

(Sunarwo, Supriyo, 2015)

Dimana:

$H R_{T}$ : Heat rate turbin $(\mathrm{kJ} / \mathrm{kWh})$

$\dot{m}_{1}$ :Laju aliran massa main steam(uap keluaran superheater) $(\mathrm{kg} / \mathrm{h})$

$h_{1}$ :Entalpimain steam(uap keluaran superheater) $(\mathrm{kJ} / \mathrm{kg})$

$\dot{m}_{3}$ :Laju aliran massa hot reheat (uap keluaran dari reheater $)(\mathrm{kg} / \mathrm{h})$

$h_{3}$ : Entalpi hot reheat steam (uap keluaran reheater) $(\mathrm{kJ} / \mathrm{kg})$

$\dot{m}_{f}$ :Laju aliran massa feed water (air umpan boiler) $(\mathrm{kg} / \mathrm{h})$ $h_{f}$ :Entalpifeed water (air umpan boiler) $(\mathrm{kJ} / \mathrm{kg})$

$\dot{m}_{2}$ :Laju aliran massa cold reheat (uap masuk ke reheater) $(\mathrm{kg} / \mathrm{h})$

$h_{2}$ :Entalpicold reheat (uap masuk ke reheater) $(\mathrm{kJ} / \mathrm{kg})$

$\dot{m}_{i s}$ :Laju aliran massa superheater $\operatorname{spray}(\mathrm{kg} / \mathrm{h})$

$h_{s s}:$ :Entalpisuperheater $\operatorname{spray}(\mathrm{kJ} / \mathrm{kg})$

$p_{g}$ :Turbin generator output (MW)

$p_{\text {exc }}$ :Generator excitation power (MW)

Untuk mencari laju aliran massa main steam(uap keluaran superheater) $\dot{m}_{1}$, laju aliran massa cold reheat (uap masuk ke reheater) $\dot{m}_{2}$, dan laju aliran massa hot reheat (uap keluaran dari reheater) $\dot{m}_{3}$, dapat dicari menggunakan persamaan:

$$
\begin{aligned}
& \dot{m}_{1}=\dot{m}_{f}+\dot{m}_{i s}+\dot{m}_{m u} \\
& \quad \dot{m}_{2}=\dot{m}_{1}-G s_{1}-\dot{m}_{e x 1}-\dot{m}_{e x 2} \\
& \dot{m}_{3}=\dot{m}_{2}+\dot{m}_{i r}
\end{aligned}
$$

Dimana:

$\dot{m}_{1}$ :laju aliran massa main steam(uap keluaran superheater $)(\mathrm{kg} / \mathrm{h})$

$\dot{m}_{f}$ :laju aliran massa feed water (air umpan boiler) $(\mathrm{kg} / \mathrm{h})$

$\dot{m}_{i s}$ :laju aliran massa superheater $\operatorname{spray}(\mathrm{kg} / \mathrm{h})$

$\dot{m}_{m u}$ :total aliran massa $(\mathrm{kg} / \mathrm{h})$

$\dot{m}_{2}$ :laju aliran massa cold reheat (uap masuk ke reheater) $(\mathrm{kg} / \mathrm{h})$

$\dot{m}_{1}$ :laju aliran massa main steam(uap keluaran superheater $)(\mathrm{kg} / \mathrm{h})$

$G s_{1}:$ hp gland seal and MSV Leakage $(\mathrm{kg} / \mathrm{h})$

$\dot{m}_{e x} 1$ :ekstraksi aliran uap ke pemanas 1 $(\mathrm{kg} / \mathrm{h})$

$\dot{m}_{e x} 2$ :ekstraksialiran uap ke pemanas 2 $(\mathrm{kg} / \mathrm{h})$

$\dot{m}_{3}$ :laju aliran massa hot reheat (uap keluaran dari reheater) $(\mathrm{kg} / \mathrm{h})$

$\dot{m}_{2}$ :laju aliran massa cold reheat (uap masuk ke reheater) $(\mathrm{kg} / \mathrm{h})$

$\dot{m}_{\text {ir }}$ :aliran semprot reheater $(\mathrm{kg} / \mathrm{h})$

\section{METODE PENELITIAN}

Dalam penulisan penelitian ini tedapat beberapa tahapan-tahapan selama penelitian sebagai berikut:

1. Persiapan Awal

Mempersiapkan hal-hal yang dilakukan sebelum melakukan proses penelitian

2. Studi Pustaka 
Mencari sumber teori dari buku pelajaran, internet, dan jurnal yang sesuai dengan judul yang telah disetujui oleh pembimbing sebagai landasan teori penelitian yang dilaksanakan.

3. Studi Lapangan

Melakukan observasi ditempat dilakukannya penelitian yang sebelumnya sudah meminta izin kepihak HRD PT. INDONESIA POWER UBOH UJP BANTEN 3 LONTAR (PLTU) juga melakukan sesi wawancara dengan pertanyaan yang sesuai pada judul penelitian. Wawancara dilakukan baik dengan pembimbing lapangan, operator, juga pihakpihak terkait dengan penelitian.

4. Pengumpulan Data

Dalam penelitian ini, teknik pengumpulan data merupakan faktor penting demi keberhasilan penelitian. Hal ini berkaitan dengan bagaimana cara mengumpulkan data dan sumber pengumpulan data yang digunakan. Jenis sumber data adalah mengenai darimana data diperoleh apakah data diperoleh dari sumber langsung (primer) atau data diperoleh dari sumber tidak langsung (sekunder).

5. Pengolahan Data

Tahap pengolahan data ini dilakukan sebagai tindak lanjut dari pengumpulan data. Pengolahan data ini didapatkan terhadap data yang sudah ada seperti data-data input dan output pada heatrate yang akan menentukan nilai dari turbine heatrate sebagaimana sesuai dengan penelitian.

6. Hasil Penelitian

Merupakan suatu hasil yang dilakukan peneliti sehingga dapat dibuat sebagai penelitian berupa rumus.

7. Analisa dan Pembahasan

Setelah data diolah dan dikumpulkan, maka selanjutnya menganalisa dan untuk mengetahui hasil nilai turbine heatrate unit 1 pada tahun 2016 yang selanjutnya kemudian akan dibahas secara terperinci sesuai data-data yang aktual yang telah diperoleh.

\section{ANALISA DAN PEMBAHASAN \\ a. Pengumpulan Data}

Berikut data yang dipakai dalam perhitungan nilai turbine heatrate berdasarkan performance testyang menggunakan sampel data Unit 1 pada bulan Januari 2016.

Tabel 4.1 Data Sampel Turbine Heatrate Unit 1 Pada Bulan Januari 2016

\begin{tabular}{|l|c|}
\hline \multicolumn{1}{|c|}{ Unit 1} & $\begin{array}{c}\text { Januari } \\
\mathbf{2 0 1 6}\end{array}$ \\
\hline Enthalpy Main Steam $h_{2}(\mathrm{~kJ} / \mathrm{kg})$ & 3404.01 \\
\hline Enthalpy Cold Reheat $\mathrm{h}_{2}(\mathrm{~kJ} / \mathrm{kg})$ & 3080.20 \\
\hline Enthalpy Hot Reheat $h_{3}(\mathrm{~kJ} / \mathrm{kg})$ & 3536.85 \\
\hline Enthalpy Feed Water $h_{f}(\mathrm{~kJ} / \mathrm{kg})$ & 1192.19 \\
\hline Laju Aliran Masa Main Steam $\dot{m}_{1}(\mathrm{~kg} / \mathrm{h})$ & 922211.12 \\
\hline Laju Aliran Masa Cold Reheat $\dot{m}_{2}(\mathrm{~kg} / \mathrm{h})$ & 782009.66 \\
\hline Laju Aliran Masa Hot Reheat $\dot{m}_{3}(\mathrm{~kg} / \mathrm{h})$ & 794695.65 \\
\hline Laju Aliran Masa Feed Water $\dot{m}_{f}(\mathrm{~kg} / \mathrm{h})$ & 868657.15 \\
\hline Laju Aliran Masa Superheater Spray $\dot{m}_{i s}(\mathrm{~kg} / \mathrm{h})$ & 50315.62 \\
\hline Turbin Generator output $p_{g}(\mathrm{MW})$ & 298.81 \\
\hline Generator Excitationp $p_{s x c}(\mathrm{MW})$ & 0.72 \\
\hline
\end{tabular}

\section{b. Perhitungan TurbineHeatrate}

Turbine heat rate menunjukkan perbandingan dari energi total yang digunakan untuk memutar turbin, dengan energi listrik yang dihasilkan oleh generator dan dinyatakan dalam $\mathrm{kJ} / \mathrm{KWh}$. Nilai turbine heat rate dapat dihitung dengan data sampel pada bulan Januari 2016 unit 1.

Untuk mencari laju aliran massa main steam (uap keluaran superheater) $\dot{m}_{1}$, laju aliran massa cold reheat (uap masuk ke reheater) $\dot{m}_{2}$, dan laju aliran massa hot reheat (uap keluaran dari reheater) $\dot{m}_{3}$, dapat dicari menggunakan data sampelunit 1 bulan Januari 2016:

a. Laju aliran massa main steam (uap keluaran superheater)

Diketahui:

$$
\begin{aligned}
& \dot{m}_{f}=868657.15 \mathrm{~kg} / \mathrm{h} \\
& \dot{m}_{i s}=50315.62 \mathrm{~kg} / \mathrm{h} \\
& \dot{m}_{\text {mu }} \quad=3238.35 \mathrm{~kg} / \mathrm{h} \\
& \text { Jawab: } \\
& \dot{m}_{1}=\dot{m}_{f}+\dot{m}_{i s}+\dot{m}_{m u} \\
& \quad=868657.15+50315.62+3238.35 \\
& \quad=922211.12 \mathrm{~kg} / \mathrm{h}
\end{aligned}
$$

b. Laju aliran massa cold reheat (uap masuk ke reheater)

Diketahui:

$$
\begin{aligned}
& \dot{m}_{1}=922211.12 \mathrm{~kg} / \mathrm{h} \\
& G s_{1}=21295.60 \mathrm{~kg} / \mathrm{h} \\
& \dot{m}_{\text {ex } 1}=48468.91 \mathrm{~kg} / \mathrm{h} \\
& \dot{m}_{\text {ex } 2}=70436.95 \mathrm{~kg} / \mathrm{h} \\
& \mathrm{Jawab}: \\
& \dot{m}_{2}=\dot{m}_{1}-G s_{1}-\dot{m}_{\text {ex1 }}-\dot{m}_{\text {ex } 2} \\
& =922211.12-21295.60- \\
& \quad 48468.91-70436.95 \\
& \quad=782009.66 \mathrm{~kg} / \mathrm{h}
\end{aligned}
$$


c. Laju aliran massa hot reheat (uap keluaran dari reheater)

Diketahui:

$$
\begin{aligned}
\dot{m}_{2} & =782009.66 \mathrm{~kg} / \mathrm{h} \\
\dot{m}_{\text {ir }} & =12685.99 \mathrm{~kg} / \mathrm{h} \\
\mathrm{Jawab} & \\
\dot{m}_{3} & =\dot{m}_{2}+\dot{m}_{i r} \\
& =782009.66+12685.99 \\
& =794695.65 \mathrm{~kg} / \mathrm{h}
\end{aligned}
$$

d. Perhitungan TurbineHeat Rate

$$
H R_{T}=\frac{\begin{array}{c}
\left(\dot{m}_{1} \times h_{1}+\dot{m}_{3} \times h_{3}\right)- \\
\left(\dot{m}_{f} \times h_{f}+\dot{m}_{2} \times h_{2}+\dot{m}_{i s} \times h_{s s}\right)
\end{array}}{p_{g}-p_{\text {exc }}}
$$

Diketahui:

$$
\begin{array}{lll}
\dot{m}_{1} & =922211.12 & \mathrm{~kg} / \mathrm{h} \\
\dot{m}_{2} & =782009.66 & \mathrm{~kg} / \mathrm{h} \\
\dot{m}_{3} & =794695.65 & \mathrm{~kg} / \mathrm{h} \\
h_{1} & =3404.01 & \mathrm{~kJ} / \mathrm{kg} \\
h_{2} & =3080.20 & \mathrm{~kJ} / \mathrm{kg} \\
h_{3} & =3536.85 & \mathrm{~kJ} / \mathrm{kg} \\
\dot{m}_{f} & =868657.15 & \mathrm{~kg} / \mathrm{h} \\
\dot{m}_{i s} & =50315.62 & \mathrm{~kg} / \mathrm{h} \\
h_{f} & =1192.19 & \mathrm{~kJ} / \mathrm{kg} \\
h_{s s} & =905.53 & \mathrm{~kJ} / \mathrm{kg} \\
p_{g} & =298.81 & \mathrm{MW} \\
p_{\text {exc }} & =0.72 & \mathrm{MW}
\end{array}
$$

Dimana $1 \mathrm{~kJ}=\frac{1}{4.1868} \mathrm{kcal}$

Jawab:

$$
\begin{aligned}
& \left(\dot{m}_{1} \times h_{1}+\dot{m}_{3} \times h_{3}\right)- \\
& H R_{T}=\frac{\left(\dot{m}_{f} \times h_{f}+\dot{m}_{2} \times h_{2}+\dot{m}_{i s} \times h_{s s)}\right.}{p_{g-} p_{\text {exc }}} \\
& (922211.12 \times 3404.01+) \\
& 794695.65 \times 3536.85) \\
& (868657.15 \times 1192.19+ \\
& 782009.66 \times 3080.20+ \\
& H R_{T}=\frac{50315.62 \times 905.53)}{298.81-0.72} \\
& =\frac{5949935184.29-3489912825.76}{298.09} \\
& =\frac{2460022358.53}{298.09} \\
& =8252.61 \mathrm{~kJ} / \mathrm{kWh} \\
& =\frac{8252.61}{4.1868}=1971.10 \mathrm{kcal} / \mathrm{kWh}
\end{aligned}
$$

\section{c. Pembahasan Hasil Penelitian}

Dari hasil perhitungan heatrate berdasarkan performance test unit 1 tahun 2016 maka didapatkan hasil nilai heatrate dengan metode perhitungan turbine heatrate mempunyai hasil seperti tabel 4.1 sebagai berikut:
Tabel 4.1 Hasil Turbine HeatratePada Tahun 2016

\begin{tabular}{|l|c|c|}
\hline \multirow{2}{*}{ Bulan } & \multicolumn{2}{c|}{ Unit 1 } \\
\cline { 2 - 3 } & $\mathbf{k J} / \mathbf{k W h}$ & Kcal/kWh \\
\hline Januari & 8252.61 & 1971.1 \\
\hline Februari & 8584.71 & 2050.42 \\
\hline Maret & 8911.99 & 2128.59 \\
\hline April & 8724.8 & 2083.88 \\
\hline Mei & 8828.23 & 2108.58 \\
\hline Juni & 8829.78 & 2108.95 \\
\hline Juli & - & - \\
\hline Agustus & 8614.49 & 2057.53 \\
\hline September & 8490.76 & 2027.98 \\
\hline
\end{tabular}

Dari data hasil perhitungan pada tabel 4.1 maka dapat dibuat grafik untuk memudahkan pembahasan hasil data. Gambar 4.1 dibawah ini menggambarkan grafik hasil perhitungan turbine heatrate berdasarkan performance test pada unit 1

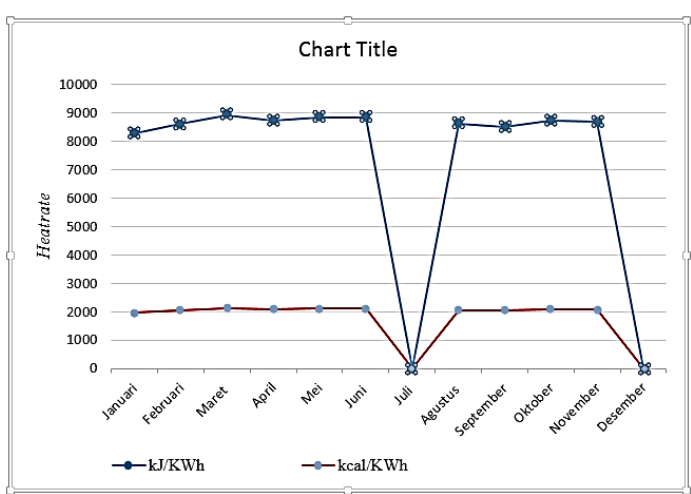

Gambar 4.1 Grafik Hasil Perhitungan Turbine heatrate

Dari data hasil perhitungan performance test unit 1 pada tabel 4.1 dapat diketahui bahwa nilai turbine heatrate mengalami kenaikan dan penurunan yang tidak begitu signifikan nilai turbine heatrate terendah terjadi pada bulan Januari dengan nilai 8252.61 dan nilai turbin heatrate tertinggi terjadi pada bulan Maret dengan nilai 8911.99. kenaikan dan penurunan turbin heatrate tersebut dapat dilihat pada gambar grafik 4.1.

\section{KESIMPULAN}

Dari hasil perhitungan dan Analisa heatrate dengan metode perhitungan turbine heatrate berdasarkan performance test pada unit 1 dapat diambil kesimpulan sebagai berikut:

1. Nilai turbine heatrate terendah (terbaik) terdapat pada bulan Januari dengan nilai $8252.61 \mathrm{~kJ} / \mathrm{kWh}$ sedangkan nilai turbine 
heatrate tertinggi (terburuk) terdapat pada bulan Maret dengan nilai 8911.99 $\mathrm{kJ} / \mathrm{kWh}$. Semakin kecil nilai heatrate maka akan semakin baik efisiensi pembangkit, sebaliknya jika semakin tinggi (besar) nilai heatrate maka semakin buruk efisiensi pembangkit tersebut. Hasil nilai turbine heatrate berdasarkan performance test mengalami kenaikan dan penurunan yang tidak begitu signifikan.

2. Data diambil dari Central Control Room (CCR) pada PLTU Banten 3 Lontar dan hasil perhitungan performance test dari data CCR dengan cara perhitungan manual tidak berbeda jauh hasilnya.

\section{DAFTAR PUSTAKA}

Berbagi Energi - Hendra Yudisaputro Minggu, 22 maret 2015 -

http://berbagienergi.com/2015/03/22/heatrate-input-output/

Kulshrestha, S. k. 1989. Buku teks Termodinamika Terpakai, Teknik Uap dan Panas. Jakarta: Universitas Indonesia (UI - Press).
Michael J. Moran, Howard N. Shapiro. 2004. Termodinamika Teknik Jilid II. Jakarta: Erlangga

Manual Book PT Indonesia Power Uboh UJP Banten 3 Lontar

P. Shlyakin. 1990. Turbin Uap Teori Dan Rancangan. Jakarta: Erlangga

Pembangkit Listrik - Engineering RE \& Alumni Portal - Senin, 30 maret 2015

http://berbagienergi.com/2015/03/22/h eat-rate-input-output/

Sunarwo, Supriyo. Analisa Heat Rate Pada Turbin Uap Berdasarkan Performance Test Pltu Tanjung Jati B Unit 3. Jurnal Teknik Energi, Vol 11 No. 3 September 2015, 61-68

Wordpress - Ahmad Abdul Qodir - Sabtu, 10 januari 2015 https://aabdulqodir.wordpress.com/20 15/01/10/heat-rate-power-plant/

Yunus A. Cengel And Michael A. Boles, Mc Graw-Hill Higher Education. 2007. Thermodynamics: An Engineering Approach. 